\title{
On the wind stress formulation over shallow waters in atmospheric models
}

\section{P. A. Jiménez ${ }^{1,2}$ and J. Dudhia ${ }^{3}$}

${ }^{1}$ National Center for Atmospheric Research, Research Applications Laboratory, Boulder, CO, USA

${ }^{2}$ CIEMAT, División de Energías Renovables, Madrid, Spain

${ }^{3}$ National Center for Atmospheric Research, Mesoscale and Microscale Meteorology Division, Boulder, CO, USA

Received: 26 October 2014 - Accepted: 25 November 2014 - Published: 18 December 2014 Correspondence to: P. A. Jimenez (jimenez@ucar.edu)

Published by Copernicus Publications on behalf of the European Geosciences Union.

\section{On the wind stress formulation over shallow waters in atmospheric models \\ P. A. Jiménez and \\ J. Dudhia}

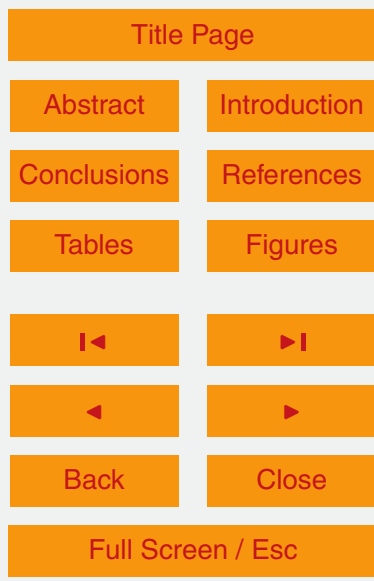

Printer-friendly Version

Interactive Discussion 


\section{Abstract}

The wind stress formulation over shallow waters is investigated using year-long observations of the wind profile within the first $100 \mathrm{~m}$ of the atmosphere and mesoscale simulations. The model experiments use a range of planetary boundary layer parame5 terizations in order to quantify the uncertainty related to the turbulent closure assumptions, and thus isolate the dominant influence of the roughness formulation. Results indicate that a positive wind speed bias exists when the common open ocean formulation for roughness is adopted. An alternative formulation consistent with shallow water observations is necessary to reconcile model results with observations, providing the first modeling evidence supporting the increase of surface drag over shallow waters. Including ocean bathymetry as static input data to atmospheric models constitutes an area where further research should be oriented.

\section{Introduction}

The roughness of the ocean is mainly controlled by the wave field which is in turn 15 determined to a large extent by the wind (Edson et al., 2013). In general, the ocean surface is rougher for increasingly higher winds. Over the open ocean, a modified version of the Charnock relationship (Charnock, 1955) provides a good representation of the feedback between the wind speed and the surface roughness (Edson et al., 2013). However, data from field campaigns have revealed that over shallow waters the roughness of the surface is higher than the corresponding values over the open ocean (Geernaert et al., 1986, 1987; Smith et al., 1992; DeCosmo et al., 1996; Taylor and Yelland, 2001). In spite of this differentiated behavior, atmospheric models apply the same wind stress formulation regardless of the depth of the waters.

Here we show that a significant bias exists when compared to tower data in shal25 low waters, and that an alternative formulation is necessary to adequately reproduce the low-level wind speed climatology. In particular, we found that increasing the surface
GMDD

7, 9063-9077, 2014

On the wind stress

formulation over

shallow waters in

atmospheric models

P. A. Jiménez and

J. Dudhia

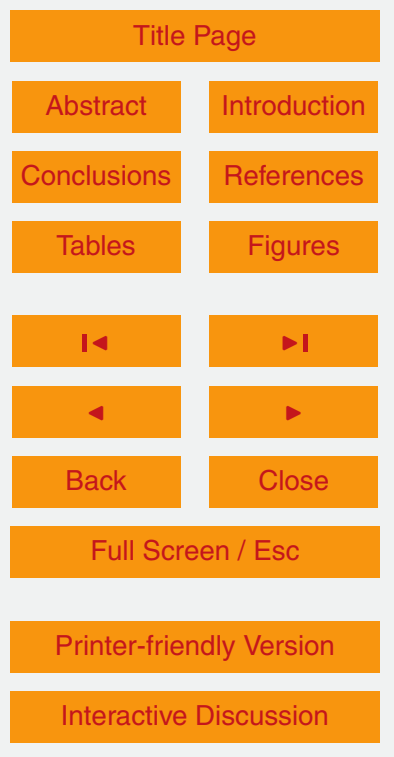


drag is necessary to reconcile model results with observations of the wind profile within the first $100 \mathrm{~m}$ of the atmosphere. The alternative formulation consists of a linear relationship between the wind and the logarithm of the aerodynamic roughness length $\left(z_{0}\right)$ and this increased drag is consistent with observations acquired over shallow waters 5 during the Humidity Exchange Over the Sea (HEXOS) program (DeCosmo et al., 1996; Janssen, 1997). Our results demonstrate the necessity of introducing a different representation of the surface drag over shallow waters from the one over the open ocean; this being the first modeling evidence supporting the increase of the ocean roughness found in the field campaigns.

\section{Observational evidence}

Observational evidence indicates that the surface drag over the ocean is a positive function of the wind speed (Jones and Toba, 2001). Using non-dimensional arguments Charnock (Charnock, 1955) postulated that $z_{0}$ is proportional to the square of the friction velocity $\left(u_{*}\right)$, a variable that represents the intensity of the atmospheric turbulent mixing of momentum associated with surface friction:

$z_{0}=\frac{a}{g} u_{*}^{2}$

$g$ is the gravity acceleration whereas the factor $a$ is an empirical constant known as the Charnock parameter. Subsequent field experiments have reported a range of values for the parameter (Geernaert et al., 1986; Kitaigorodskii and Volkov, 1965; Wu, 1982; Garrat, 1977). More recent empirical evidence suggests a dependence of the Charnock parameter on the wind speed (Edson et al., 2013; Fairall et al., 2003), or even on the sea state (Smith et al., 1992; Fairall et al., 2003; Donelan, 1990; Oost et al., 2002). Nowadays, the Coupled Ocean-Atmosphere Response Experiment (COARE) algorithm provides the most widely used relationship. A satisfactory agreement over
On the wind stress

formulation over

shallow waters in

atmospheric models

P. A. Jiménez and

J. Dudhia

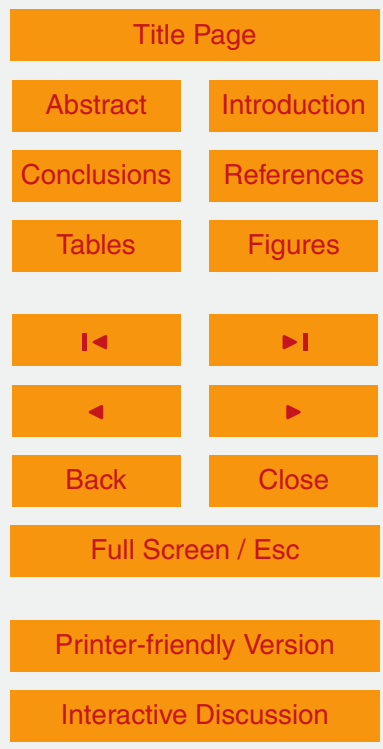


using a Charnock parameter that is a function of the wind speed (Edson et al., 2013, 2014).

There is an agreement that over shallow waters the sea is rougher than over the open ocean for a given wind speed (Geernaert et al., 1986, 1987; Smith et al., 1992;

5 DeCosmo et al., 1996; Taylor and Yelland, 2001; Foreman and Emeis, 2010). The added drag over shallow waters is increasingly larger for higher winds in comparison with the values over the open ocean. The physical mechanism responsible for this effect is unclear, but it has been speculated to be associated with the effects of the bottom of the ocean that tends to slow down the phase speed of the waves which 10 become shorter and steeper in an effect known as shoaling (Foreman and Emeis, 2010); or with form drag due to short (young) waves (DeCosmo et al., 1996). In spite of the different properties of the sea surface, regional and global atmospheric models widely use a roughness formulation such as Eq. (1) with a Charnock parameter valid for the open ocean. We will show that models using the standard formulation are sys-

15 tematically overestimating the lower level winds over regions with shallow waters and hypothesize that this is because the drag over these regions is higher in comparison with the open ocean. Since the added drag is increasingly larger for higher winds, this explains why the overestimation was an increasing function of the wind speed.

\section{Experimental design}

20 We have performed a series of modeling experiments with version 3.5.1 of the Weather Research and Forecasting (WRF) model (Skamarock et al., 2005). WRF is a state of the art regional atmospheric model designed for both operational and research needs. In order to obtain statistically robust conclusions, we simulated the atmospheric evolution over a coastal region during a complete year wherein observations of the wind speed were available at a total of eight levels within the first $100 \mathrm{~m}$ of the atmosphere. The observations were acquired at the research platform FINO 1 located at about $48 \mathrm{~km}$ from the German coast with a depth of about $30 \mathrm{~m}$. The year of 2009 was se-

On the wind stress

formulation over

shallow waters in

atmospheric models

P. A. Jiménez and

J. Dudhia

\section{Title Page}

Abstract

Introduction

Conclusions

Tables

References

Figures

14

$\triangleleft$

$\rightarrow 1$

$\checkmark$

Back

Close

Full Screen / Esc

Printer-friendly Version

Interactive Discussion 
lected due to the availability of data at all the levels and its near climatological wind conditions.

The physical and dynamical settings used in the WRF simulations are essentially the same as those used in previous studies (Jiménez et al., 2009, 2011a, b). The model is 5 initialized at 00:00 UTC of each day and run for $48 \mathrm{~h}$ recording the output every hour. The first day is discarded as a spin up of the model and the second day is retained as the simulation for that day. The process is repeated until obtaining a simulation for each day of the year of 2009. Data from the ERA-Interim reanalysis (Dee et al., 2011) are used as initial and boundary conditions. Sensitivity experiments were performed to 10 the horizontal resolution. Different simulations were performed at 27,9 and $3 \mathrm{~km}$ with very little sensitivity in the wind speed distribution so the simulations herein presented were performed at $27 \mathrm{~km}$ of horizontal resolution. A total of 36 vertical levels were used in the vertical with 5 of them within the first $200 \mathrm{~m}$ of the atmosphere.

Realizing the importance that the closure assumptions associated with the represen15 tation of the turbulent mixing within the planetary boundary layer (PBL) may exert on the results, we used a total of 4 different PBL parameterizations (Hong et al., 2006; Pleim, 2007; Nakanishi and Niino, 2009; Bretherton and Park, 2009) in each experiment to quantify the uncertainty related to the turbulence closure. The first one imposes the shape of the vertical profile of the eddy diffusivities (K-profile method) in a first order closure (Hong et al., 2006). The second one is based on a combination of a transilient approach with a local scheme and is also a first order closure (Pleim, 2007). The third and fourth parameterizations impose a 1.5 order closure that resolve the turbulent kinetic energy equation to compute the eddy diffusivities (Nakanishi and Niino, 2009; Bretherton and Park, 2009). These two last parameterizations mainly differ in the turbulent length-scale formulation. This experimental design allows us to quantify the uncertainty related to the turbulent closure in order to isolate the effects of the roughness formulation. To avoid timing errors associated with the tails of the wind speed distribution that can mask systematic errors, we focus on the frequency distribution characteristics only.

On the wind stress

formulation over

shallow waters in

atmospheric models

P. A. Jiménez and

J. Dudhia

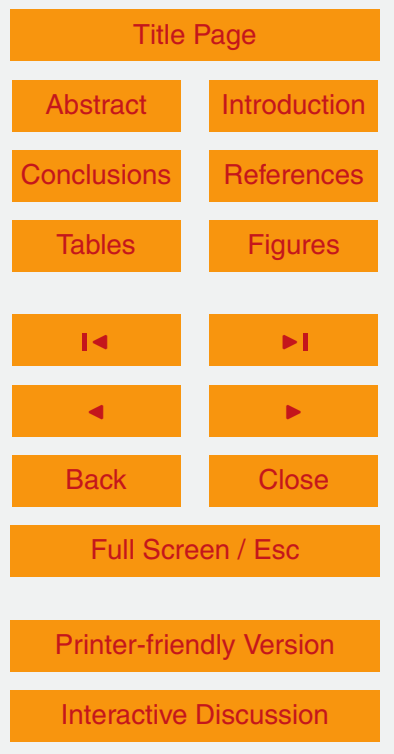




\section{Wind stress formulation}

The comparison of the observed and simulated wind speed distributions calculated with data corresponding to the $8760 \mathrm{~h}$ of 2009 is shown, for the sensor located at $60 \mathrm{~m}$, as a percentile-percentile comparison in Fig. 1 (red area). Clearly, modeling re5 sults indicate a progressive overestimation of the frequency of moderate-high wind speeds. Data from all sensors are in close agreement with this finding. The systematic overestimation for all the formulations of the turbulent mixing points to limitations in the representation of the ocean-atmosphere interactions as a potential source of the discrepancies. Indeed, the overestimation can be understood in terms of the $z_{0}$ formulation used by WRF that consists of a Charnock relationship, following Eq. (1) with $a=0.0185$ (Wu, 1982), consistent with values observed over the open ocean. Assuming a linear dependence of the Charnock parameter with the wind speed as reported to be more valid over the open ocean by the COARE algorithm (Edson et al., 2013, 2014) shows a small sensitivity compared to the previous estimation (green, Fig. 1). In winds.

These findings support our working hypothesis that wind over shallow waters will be overestimated, and therefore indicate the necessity of improving the representation of the ocean roughness over these regions. To further reinforce this statement, ${ }_{20} \quad$ Fig. $2 \mathrm{a}$ shows the drag coefficient $\left(C_{\mathrm{d}}\right)$ defined as the squared ratio of the friction velocity and the wind speed at $10 \mathrm{~m}: C_{\mathrm{d}}=u_{*}^{2} / u_{10}^{2}$. The symbols represent observations recorded during the international HEXOS programme (Janssen, 1997) that took place in the vicinity of the Dutch Noordwijk platform with $18 \mathrm{~m}$ of ocean depth. HEXOS data has been used due to the quality of the measurements and its relatively close proximity to FINO1. The $C_{d}$ values as a result of assuming a neutral atmosphere and the standard WRF formulation (red line) are in closer agreement with the open ocean formulation from the COARE algorithm (green line) than with the shallow water data from the HEXOS programme (symbols). Particularly, the drag is underestimated by both for-
GMDD

7, 9063-9077, 2014

On the wind stress

formulation over

shallow waters in

atmospheric models

P. A. Jiménez and

J. Dudhia

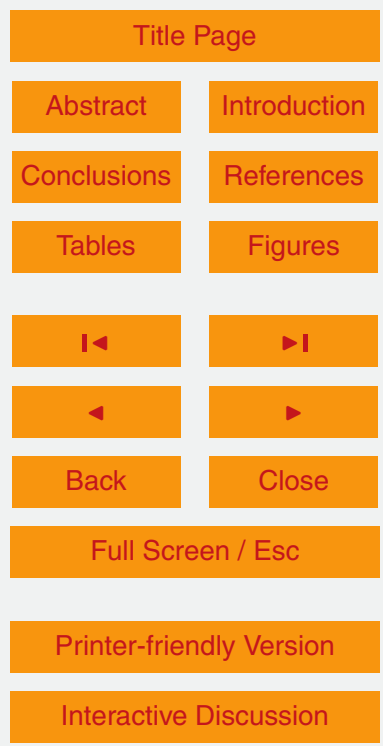


mulations for moderate-high winds supporting our previous expectations. Similar comments can be made regarding the friction velocity (Fig. 2b) that shows how the two formulations (green and red lines) are in agreement with the lower part of the observational scattering with a clear underestimation of the recorded values at moderate-high winds.

To provide complementary evidence of the importance of the roughness formulation, we have performed an additional WRF experiment for the year of 2009 modifying the $z_{0}$-wind relation in order to suppress the wind speed biases. The new formulation assumes that the logarithm of the surface roughness is a linear function of the wind speed 10 at the first model level $\left(15 \mathrm{~m}, u_{15}\right)$ :

$\log _{10}\left(z_{0}\right)=0.125 u_{15}-4.5$

where the $z_{0}$ values are consistent with the previous experiments for low winds but reach significantly higher values for moderate-high winds (Fig. 2c). A value of $0.01 \mathrm{~m}$, equivalent to the $z_{0}$ typical of grassland, is reached at $20 \mathrm{~m} \mathrm{~s}^{-1}$ giving drag coefficient 15 gre greater than 0.003 (blue, Fig. 2a). The parameters in the linear relationship have been selected in such a way that this third WRF experiment is successful in reducing the bias over the full range (blue, Fig. 1). From a modeling perspective it is better to introduce a relationship between $z_{0}$ and $u_{*}$ to remove height dependence and to add stability effects. If we assume a logarithmic wind profile typical of neutral conditions and substitute the wind speed with the one provided by the linear function (Eq. 2, blue line in Fig. 2c) we obtain:

$\ln \left(z_{0}\right)=\frac{\left(2.7 u_{*}-14.4\right)}{\left(1.39+u_{*}\right)}$

which is now a stability-dependent formula imposed in the new WRF experiment. The $u_{*}$ values obtained with this new formulation are also shown in Fig. $2 \mathrm{~b}$ (blue). The new formulation is in better agreement with the HEXOS data for the moderate-high winds capturing the increase of the ocean roughness observed over shallow waters.
GMDD

7, 9063-9077, 2014

On the wind stress

formulation over

shallow waters in

atmospheric models

P. A. Jiménez and

J. Dudhia

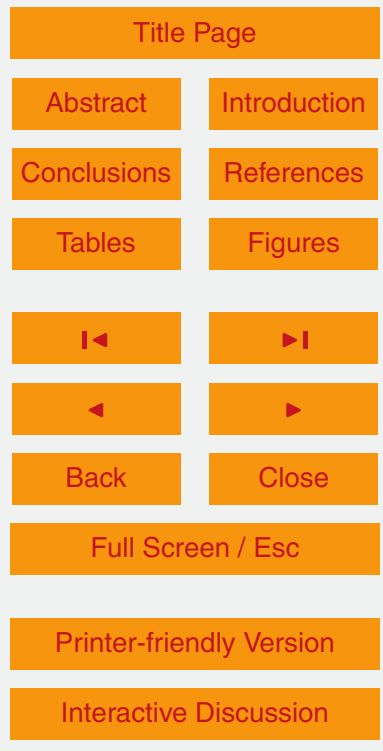


This result confirms that increasing the $z_{0}$ values over shallow waters in agreement with experimental data is necessary and sufficient to remove the overestimation of the intensity of moderate-high wind events by models (blue, Fig. 1).

To test the effect of this change on the profile for various stability conditions, we show 5 further in Fig. 3 the deviations from the percentiles calculated with observations for this new experiment and the experiment using the standard WRF formulation. Clearly, results using the new formulation (Fig. 3b) are in better agreement with observations than the standard formulation (Fig. 3a) at the three vertical levels shown. The rest of the heights with wind records available show virtually the same results indicating that 10 increasing drag, consistent with shallow water observations (Fig. 2a), improves the replication of the whole observed wind profile. Figure $3 c, d(3 e, f)$ shows the deviations subsetted for stable (unstable) conditions. The overestimation of the high-wind frequency is improved under both atmospheric stability conditions further reinforcing the attribution of the overestimation to the ocean-atmosphere interactions. It is noted

15 that the previous high-wind overestimation was especially strong in stable conditions and this was corrected well.

\section{Conclusions}

Our findings provide the first modeling evidence supporting the increase of the surface drag over shallow waters in comparison with the standard formulation derived from observations over the open ocean. Results herein presented are valid for wind speeds up to $20 \mathrm{~m} \mathrm{~s}^{-1}$, and are statistically robust given the length of the simulated period (1 year) and the consistency found between the eight vertical levels. Although a more complicated dependence of the roughness length may be anticipated, results from this study constitute a starting point towards a better representation of the ocean-atmosphere interactions in atmospheric models. For example, including ocean bathymetry as static input data can be used to discern the formulation used to represent the ocean roughness, and depth can become a parameter of the roughness representation since the
On the wind stress

formulation over

shallow waters in

atmospheric models

P. A. Jiménez and

J. Dudhia

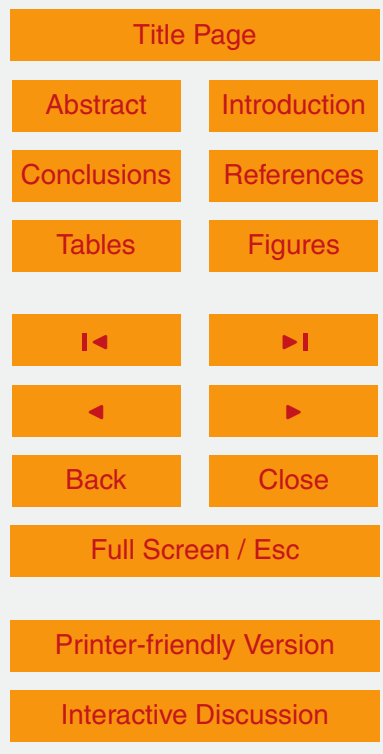


drag coefficient has been shown to increase for increasingly shallower waters (e.g. Taylor and Yelland, 2001).

The impact that the increase in the friction velocity at high winds (Fig. 2b) produces in the surface fluxes of heat and moisture also requires additional investigation. Better 5 wind estimations should be reflected in improved surface-flux estimations, in a more accurate coupling with ocean models that use the wind to derive the stress at the oceanatmosphere interface, or in improved surge estimations that, for instance, should provide better estimations of storm impacts at coastal locations. From a more applied point of view, the improved wind simulations should have a direct benefit in the wind energy industry since the number of offshore wind farms installed over shallow waters has been increasing over the last few years. This work represents an improvement in representing hub-height winds relevant to this application.

Author contributions. P. A. Jiménez and J. Dudhia conceived the ideas of the research, designed the experiment, and wrote the manuscript. P. A. Jiménez performed the WRF simula15 tions and did all the calculations.

Acknowledgements. This work was supported by project ENE2012-38772-C02-01 and was accomplished within Collaborative Agreement 09/490 between CIEMAT and NCAR. NCAR is sponsored by the National Science Foundation. J. Dudhia was supported by the National Science Foundation through the National Center for Atmospheric Research and by the Department
On the wind stress

formulation over

shallow waters in

atmospheric models

P. A. Jiménez and

J. Dudhia

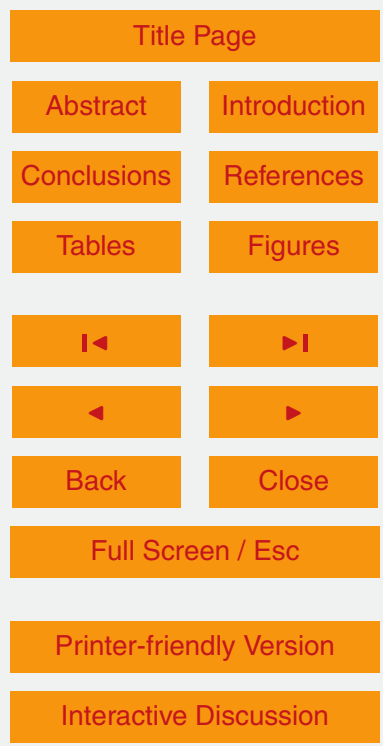




\section{References}

Bretherton, C. S. and Park, S. A.: A new moist turbulence parameterization in the Community Atmosphere Model, J. Climate, 22, 3422-3448, 2009. 9067

Charnock, H.: Wind stress on a water surface, Q. J. Roy. Meteor. Soc., 81, 639-640, 1955. 9064, 9065

DeCosmo, J., Katsaros, K. B., Smith, S. D., Anderson, R. J., Oost, W. A., Bumke, K., and Chadwick, $\mathrm{H}$.: Air-sea exchange of water vapor and sensible heat: the humidity exchange over the sea (HEXOS), J. Geophys. Res., 101, 12001-12016, 1996. 9064, 9065, 9066

Dee, D. P., Uppala, S. M., Simmons, A. J., Berrisford, P., Poli, P., Kobayashi, S., Andrae, U., Balmaseda, M. A., Balsamo, G., Bauer, P., Bechtold, P., Beljaars, A. C. M., van de Berg, L., Bidlot, J., Bormann, N., Delsol, C., Dragani, R., Fuentes, M., Geer, A. J., Haimberger, L., Healy, S. B., Hersbach, H., Hólm, E. V., Isaksen, L., Kållberg, P., Köhler, M., Matricardi, M., McNally, A. P., Monge-Sanz, B. M., Morcrette, J.-J., Park, B.-K., Peubey, C., de Rosnay, P., Tavolato, C., Thépaut, J.-N., and Vitart, F.: The ERA-Interim reanalysis: configuration and performance of the data assimilation system, Q. J. Roy. Meteor. Soc., 137, 553-597, 2011. 9067

Donelan, M. A.: The Sea: Ocean Engineering Science 9B, Wiley-Interscience, 1990. 9065

Edson, J. B., Jampana, V., Weller, R. A., Bigorre, S. P., Plueddemann, A. J., Fairall, C. W., Miller, S. D., Mahrt, L., Vickers, D., and Hersbach, H.: On the exchange of momentum over the open ocean, J. Phys. Oceanogr., 43, 1589-1610, 2013. 9064, 9065, 9066, 9068, 9075

Edson, J. B., Jampana, V., Weller, R. A., Bigorre, S. P., Plueddemann, A. J., Fairall, C. W., Miller, S. D., Mahrt, L., Vickers, D., and Hersbach, H.: Corrigendum, J. Phys. Oceanogr., 44, 2590-2590, doi:10.1175/JPO-D-14-0140.1, 2014. 9066, 9068

Fairall, C. W., Bradley, E. F., Hare, J. E., Grachev, A. A., and Edson, J. B.: Bulk parametrization of air-sea fluxes: updates and verification for the COARE algorithm, J. Climate, 14, 571-591, 2003. 9065

Foreman, R. J. and Emeis, S.: Revisiting the definition of the drag coefficient in the marine atmospheric boundary layer, J. Phys. Oceanogr., 40, 2325-2332, 2010. 9066

Garrat, J. R.: Review of drag coefficients over oceans and continents, Mon. Weather Rev., 105, 915-929, 1977. 9065

Geernaert, G. L., Katsaros, K. B., and Richter, K.: Variation of the drag coefficient and its dependence on sea state, J. Geophys. Res., 91, 7667-7679, 1986. 9064, 9065, 9066
On the wind stress

formulation over

shallow waters in

atmospheric models

P. A. Jiménez and

J. Dudhia

Title Page

Abstract

Introduction

Conclusions

Tables

References

Figures

14

4

$\rightarrow 1$

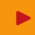

Back

Close

Full Screen / Esc

Printer-friendly Version

Interactive Discussion 
Geernaert, G. L., Larsen, S. E., and Hansen, F.: Measurements of the wind stress, heat flux, and turbulence intensity during storm conditions over the North Sea, J. Geophys. Res., 92, 13127-13139, 1987. 9064, 9066

Hong, S.-Y., Noh, Y., and Dudhia, J.: A new vertical diffusion package with an explicit treatment of entrainment processes, Mon. Weather Rev., 134, 2318-2341, 2006. 9067

Janssen, J.: Does wind stress depend on sea-state or not?, Bound.-Lay. Meteorol., 83, 479503, 1997. 9065, 9068, 9076

Jiménez, P. A., Montávez, J. P., García-Bustamante, E., Navarro, J., Jiménez-Gutiérrez, J. M., Lucio-Eceiza, E. E., and González-Rouco, J. F.: Diurnal surface wind variations over complex terrain, Física de la Tierra, 21, 79-91, 2009. 9067

Jiménez, P. A., Dudhia, J., and Navarro, J.: On the surface wind speed probability density function over complex terrain, Geophys. Res. Lett., 38, L22803, doi:10.1029/2011GL049669, 2011a. 9067

Jiménez, P. A., Vilà-Guerau de Arellano, J., González-Rouco, J. F., Navarro, J., Montávez, J. P., García-Bustamante, E., and Dudhia, J.: The effect of heatwaves and drought on the surface wind circulations in the NE of the Iberian Peninsula during the summer of 2003, J. Climate, 24, 5416-5422, 2011b. 9067

Jones, I. and Toba, Y.: Wind Stress Over the Ocean, Cambridge University Press, 2001. 9065

Kitaigorodskii, S. A. and Volkov, Y. A.: On the roughness parameter of the sea surface and the calculation of momentum flux in the near-water layer of the atmosphere, Izv. Atmos. Ocean Phy., 1, 973-988, 1965. 9065

Nakanishi, M. and Niino, H.: Development of an improved turbulence closure model for the atmospheric boundary layer, J. Meteorol. Soc. Jpn., 87, 895-912, 2009. 9067

Oost, W. A., Komen, G. J., Jacobs, C. M. J., and van Ort, C.: New evidence for a relation between wind stress and wave age from measurements during ASGAMAGE, Bound.-Lay. Meteorol., 103, 409-438, 2002. 9065

Pleim, J. E.: A combined local and nonlocal closure model for the atmospheric boundary layer, Part I: model description and testing, Bound.-Lay. Meteorol., 46, 1384-1395, 2007. 9067

Skamarock, W. C., Klemp, J. B., Dudhia, J., Gill, D. O., Barker, D. M., Wang, W., and Pow30 ers, J. G.: A Description of the Advanced Research WRF Version 2, Tech. Rep. TN468+STR, NCAR, 2005. 9066

Smith, S. D., Anderson, R. J., Oost, W. A., Kraan, C., Maat, N., DeCosmo, J., Katsaros, K., Davidson, K. L., Bumke, K., Hasse, L., and Chadwick, H. M.: Sea surface wind stress and
GMDD

7, 9063-9077, 2014

On the wind stress

formulation over

shallow waters in

atmospheric models

P. A. Jiménez and

J. Dudhia

\section{Title Page}

Abstract

Introduction

Conclusions

Tables

References

Figures

14

$\triangleleft$

$\rightarrow 1$

-

Back

Close

Full Screen / Esc

Printer-friendly Version

Interactive Discussion 
drag coefficients: the HEXOS results, Bound.-Lay. Meteorol., 60, 109-142, 1992. 9064, 9065, 9066

Taylor, P. K. and Yelland, M. J.: The dependence of sea surface roughness on the height and steepness of the waves, J. Phys. Oceanogr., 21, 572-590, 2001. 9064, 9066, 9071

Wu, J.: Wind-stress coefficients over sea surface from breeze to hurricane, J. Geophys. Res., 87, 9704-9706, 1982. 9065, 9068

\section{GMDD}

7, 9063-9077, 2014

On the wind stress

formulation over

shallow waters in

atmospheric models

P. A. Jiménez and

J. Dudhia

Title Page

Abstract

Introduction

Conclusions

References

Tables

Figures

14

4

Back

Full Screen / Esc

Printer-friendly Version

Interactive Discussion 


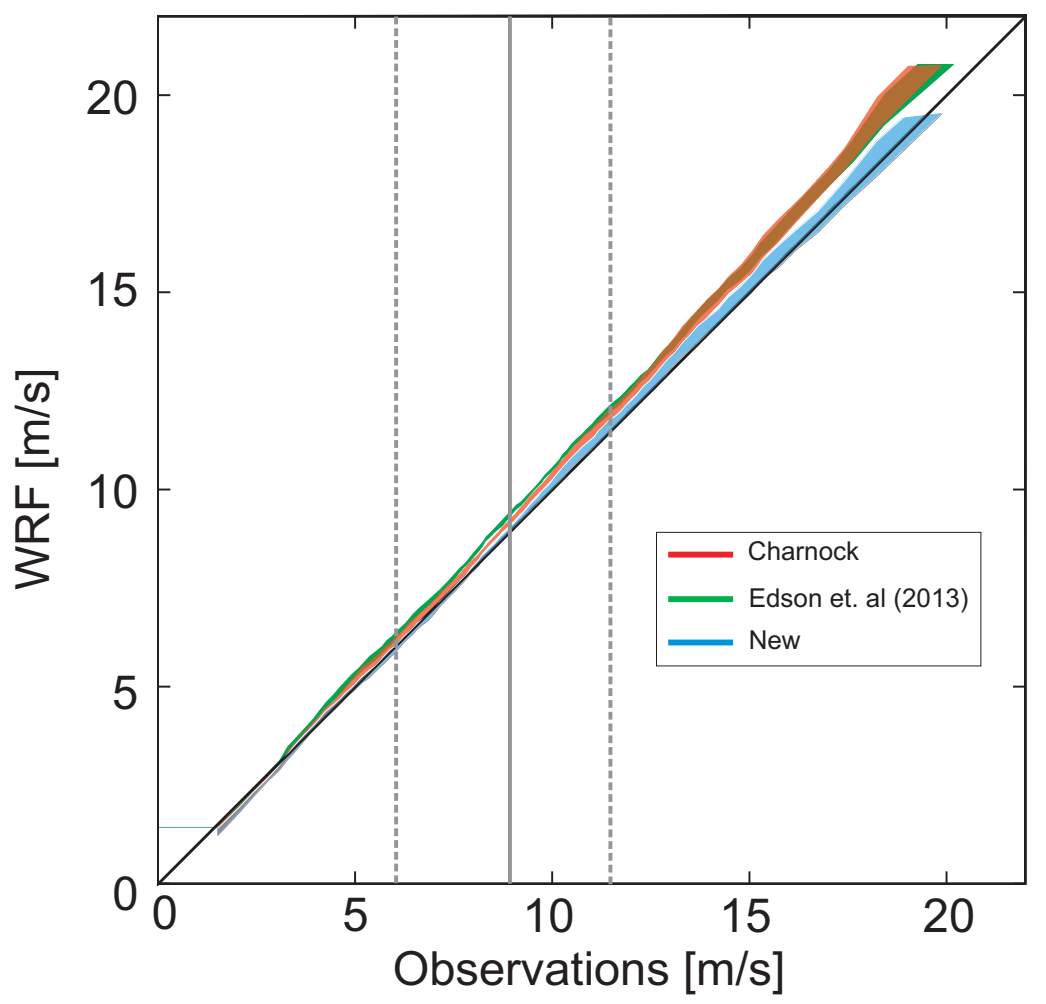

GMDD

7, 9063-9077, 2014

On the wind stress

formulation over

shallow waters in

atmospheric models

P. A. Jiménez and

J. Dudhia

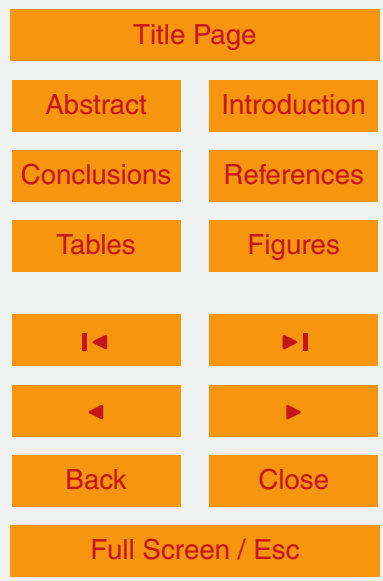

Figure 1. Percentile-percentile plot of the observed and simulated wind speed. The shaded areas comprise the results from the four different turbulence closures used in each of the three experiments (colors) performed with the WRF model: (red) standard WRF formulation, (green) the ocean roughness formulation for the open ocean from the COARE algorithm (Edson et al., 2013), and (blue) the alternative formulation herein presented. The solid gray vertical line represents the median of the observations whereas the dashed gray lines represent the 25th and 75th percentile. 

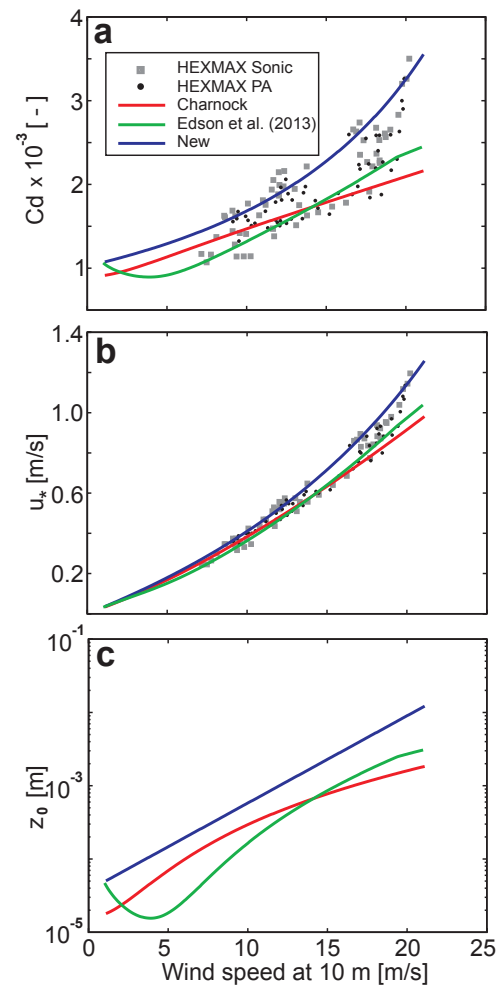

Figure 2. (a) Drag coefficient, (b) friction velocity, and (c) roughness length as a function of the $10 \mathrm{~m}$ wind speed for the three different formulations of the ocean roughness (see legend). The symbols in (a) and (b) show the data recorded during the Humidity Exchange over the Sea Main Experiment (HEXMAX) a field experiment of the HEXOS programme (Janssen, 1997). The squares are the data recorded with a sonic anemometer whereas the circles were recorded with a pressure anemometer.

\section{GMDD}

7, 9063-9077, 2014

On the wind stress

formulation over

shallow waters in

atmospheric models

P. A. Jiménez and

J. Dudhia

\section{Title Page}

Abstract

Introduction

Conclusions

References

Tables

Figures

14

\section{$\rightarrow 1$}

4

Back

Close

Full Screen / Esc

Printer-friendly Version

Interactive Discussion 


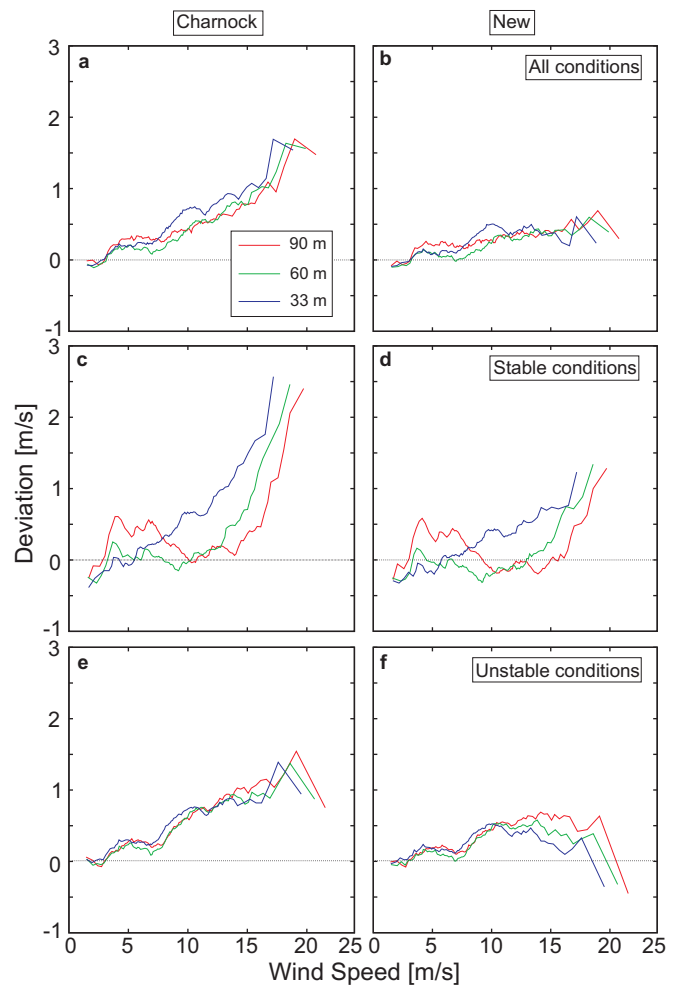

Figure 3. Deviations from the observed percentiles $(33,60$ and $90 \mathrm{~m})$ for the standard WRF experiment (left column) and the one using the shallow water formulation (right column): (first row) all the dataset, (second row) stable conditions, (third row) unstable conditions. The data used for each experiment corresponds with the average of the 4 simulations using the different parameterizations of the turbulence mixing.

On the wind stress formulation over

shallow waters in atmospheric models

P. A. Jiménez and

J. Dudhia

\section{Title Page}

\section{Full Screen / Esc}

